\title{
Imaging Fungal Contamination of Protective Organic Coatings
}

Treva Brown and Jason Lee

Naval Research Laboratory, Stennis Space Center, Mississippi, United States

Material susceptibility to biodegradation is related to both chemical/structural composition and the environment(s) to which the material is exposed. DoD planning in the recent past has focused on areas of operations that are primarily desert environments, however DoD is in the pro-active preparatory stages for a South East Asia-Pacific Rim thrust. Much of this arena is located in deep-tropical regions. No other natural environmental regions are as aggressively detrimental to materials as the deep-tropics. Materials and military forces are distinctively challenged by the high humidity, heat, rainfall, fungi/mildew and numerous other factors which combine synergistically to reduce performance. It is critical to enhance material lifetime predictive capabilities in the natural tropical environment so as to accurately identify potential material degradation, total system weaknesses and ultimately ensure successful future military operations.

It is well established that microorganisms accelerate degradation processes for organic coatings [1, 2]. Microorganisms produce extracellular chemicals (e.g., enzymes, acids and chelating agents) that are potentially deleterious to organic polymer bonds. Humidity is an important factor affecting growth of microorganisms. A level of relative humidity $(\mathrm{RH})$ above $65 \%$ increases the likelihood of microbial growth, particularly fungi. Growth of bacteria requires a RH above 95\%. Deep-tropical jungles provide a unique combination of challenges to organic coatings due to the almost constant elevated humidity (95$100 \%$ ) resulting in uninterrupted time-of-wetness, elevated temperatures, abundant atmospheric microflora and a low level of solar radiation.

Organic coating systems were applied to aluminum 2024-T3 and 7075-T6 panels with cadmium plated steel and titanium fasteners. The panels were exposed for $2+$ years outdoors in the deep tropics of South American. Fungal growth, as exhibited by a black biofilm, was observed on all organic coatings to differing degrees. Significant fungal growth was not observed on bare metal surfaces. Coating systems with metallic magnesium pigmented primers (magnesium rich primers) suppressed fungal growth regardless of the overlying top coat type. Oxidized magnesium primers did not afford the same fungal inhibition. Fungal growth was significantly de-pressed around fasteners coated with cadmium. Fungal growth was most severe on panels with aluminum rich primer.

\section{References}

[1] D.M. Lavoie, B.J. Little, R.I. Ray, K.R. Hart, P.A. Wagner, Microfungal degradation of polyurethane paint and corrosion of aluminum alloy in military helicopters, CORROSION / 97, NACE International, New Orleans, LA, 1997, pp. 7.

[2] R.I. Ray, B.J. Little, E.S. Arafat, A Laboratory Evaluation of Corrosion Preventive Compounds and Mildew Inhibitors in the Presence of Fungi, Naval Research Laboratory, Stennis Space Center, MS, 2010, pp. 19.

Figure 1. Localized images of a coated aluminum 7075-T6 substrate illustrating the different fungal growth patterns as a function of distance from the $\mathrm{Cd} /$ steel fasteners. Regions close to $\mathrm{Cd} /$ steel are free of fungal growth as are the bare metal scribes. 


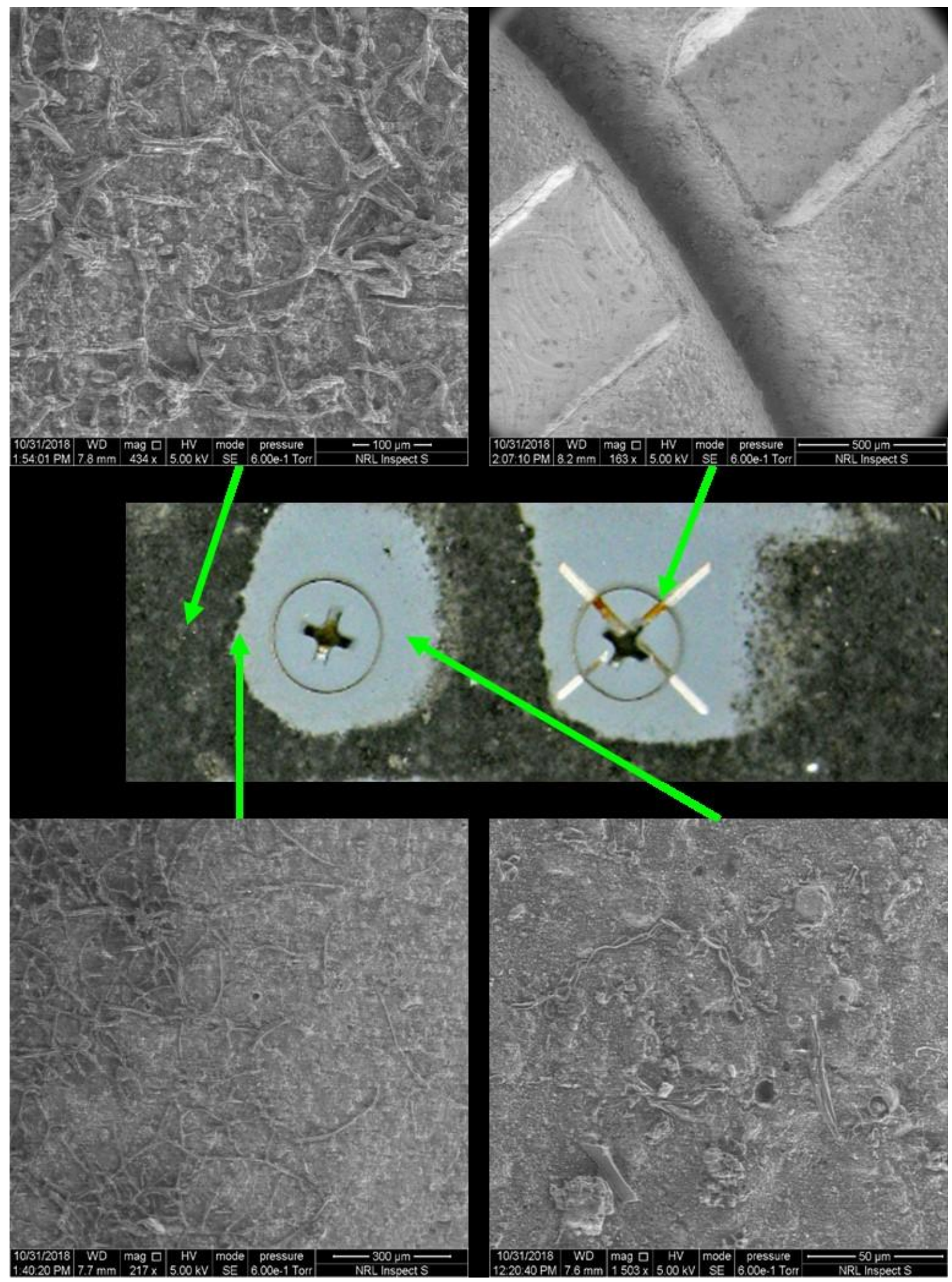

